\title{
SOLUTION FOR SYNCHRONIZING TWO BELT CONVEYERS USING MOTORS WITH DIFFERENT SPEEDS DRIVE
}

\author{
Adelina BOSTAN, Mihaela Dorica STROIA, Cornel HAȚIEGAN \\ "Babes-Bolyai" University, Cluj-Napoca, Romania \\ adelina.bostan@ubbcluj.ro, mihaela.stroia@ubbcluj.ro, cornel.hatiegan@ubbcluj.ro
}

\begin{abstract}
It is known that main aspect at a belt conveyor functioning is speed control. This issue has a greater impact upon a process when two or more belt conveyers must work together in order to obtain high quality products. In this case we talk about, not only speed controlling, but of another important aspect, synchronization of belt conveyers. Present paper describes a solution designed and implemented for synchronization of two belt conveyers of different lengths. Each belt conveyer is driven by a motor. Each motor works at its own speed drive. The two conveyors are working together in a process of producing anti-slip door mats which are mainly used at inside door, decorative purpose, etc. The proposed solution is using a PLC and two variable speed drivers with different transmission ratio. This solution can be applied in processes which are divided in sub-processes that must work as a production flow.
\end{abstract}

Keywords: belt, conveyor, automation, synchronization, PLC

\section{Production processes based on synchronized belt conveyers}

It's not a novelty that belt conveyers are widely used in various industrial fields, mainly in production processes less or more complex. Using belt conveyers brings automation to production process and with it, a list of advantages, but, when designing the proper belt conveyor for a particular type of process, there are several issues which impose particular solutions. If we talk about a simple belt conveyor main problem is speed adjustment, according to needs and taking into consideration the degree of involvement of human factor [1]. However, when we face a complex production process, one which can be split into sub-processes, that implies the use of two or more belt conveyers, another issue arises, conveyer synchronization [2,6]. Any operation of moving objects requires highprecision and fast synchronization techniques. Mechanical solutions are robust but inflexible, therefore, an automatic solution needs to be integrated into the conveyor system, in order to obtain best synchronization $[5,6]$.

Belt conveyers functioning is based on the principle of variable speed controlling. If a conveyor belt moves too slow, one can expect losses in terms of number of finished goods. As well, if a conveyor belt moves too fast, the risk of harming involved human factor increases, the obtained product may be out of line or parts of conveyor system can be damaged.

Main parts of a classical belt conveyor are: conveyor belt, carrier idlers, conveyor drive end drum, return idlers, drum bend pulleys $[3,4]$. The conveyor belt moves along carrier idlers which are driven by an electric motor by means of a variable speed drive and of a gearbox [1,7-9]. Starting from the base structure particular types of conveyers 
can be designed, depending of industrial application, types which have a more complex architecture, according to process nature.

Present paper describes a solution of automatic system for synchronizing two belt conveyers which are used in production process of anti-slip door mats which are mainly used at inside door, decorative purpose, etc. Belt conveyers have different lengths, are driven by motors with different speed and powers, their gearboxes have different ratio and for each belt conveyor a different type of variable speed drives was used. The functioning of entire process is controlled by means of one PLC [7-11].

First belt conveyor is provided with a masticator which is used to provide PVC material and a rolling mill that levels the PVC. Second belt conveyor transports textile material which will be applied on PVC. This process imposes a good synchronization of the two belt conveyers in order to obtain perfect alignment between the two materials, PVC and textile.
Following, resulted mats will pass through a baking process and afterwards through a cooling process.

\section{Designing the belt conveyers' system}

Figure 1 shows belt conveyer system design used for the process of door mat production. First belt conveyor is structured in two main parts:

- baking part which has a length of 15 meters, formed of five sections of 3 meters each, provided with two burners of $540 \mathrm{~W}$, mounted on the two sides of the belt.

- cooling part which is 15 meters long, formed of four sections of 3 meters each provided with 4 groups of 6 coolers/group, each cooler having 380 W.

Second belt conveyor consists of 3 parts, each having a length of $1.5 \mathrm{~m}$, having a slope of $45 \mathrm{o}$, designed to transport textile material to the first conveyor.

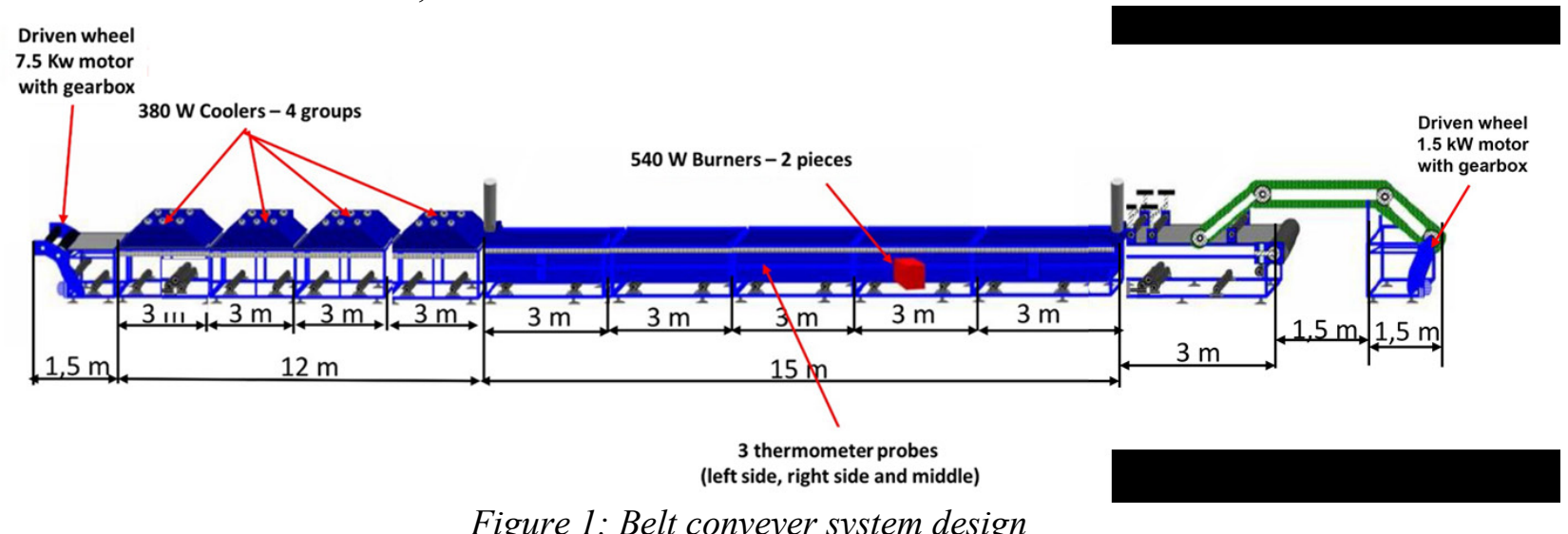

Figure 1: Belt conveyer system design

First conveyor is provided with a $7.5 \mathrm{Kw}$ three-phase motor drive having a maximum speed of $750 \mathrm{rpm}$, a slotted wheel fixed on motor drive, a gearbox having a transmission ratio of 64.7 , allowing speed controlling. Second conveyor has a $1.5 \mathrm{~kW}$ motor which has a maximum speed of 1500 rpm, a slotted wheel fixed on motor drive, a gearbox having a transmission ratio of 100 , for speed controlling.

For automation a M221 Schneider Electric PLC, an Altivar ATV930 variable speed drive for first conveyor belt and an Altivar ATV312 variable speed drive for second conveyor belt are used. The automation process is depicted in Figure 2.

Before synchronizing the two belts conveyor, functioning speed of the first conveyor must be established. In order to determine the operating parameters of the system, we consider as input data the maximum motor speed, $\mathrm{n}_{1 \max }=750 \mathrm{rpm}$, the speed transmission ratio, $\mathrm{i}=64.7$, the diameter of the drive-end drum, $\mathrm{D}=0.3 \mathrm{~m}$. 


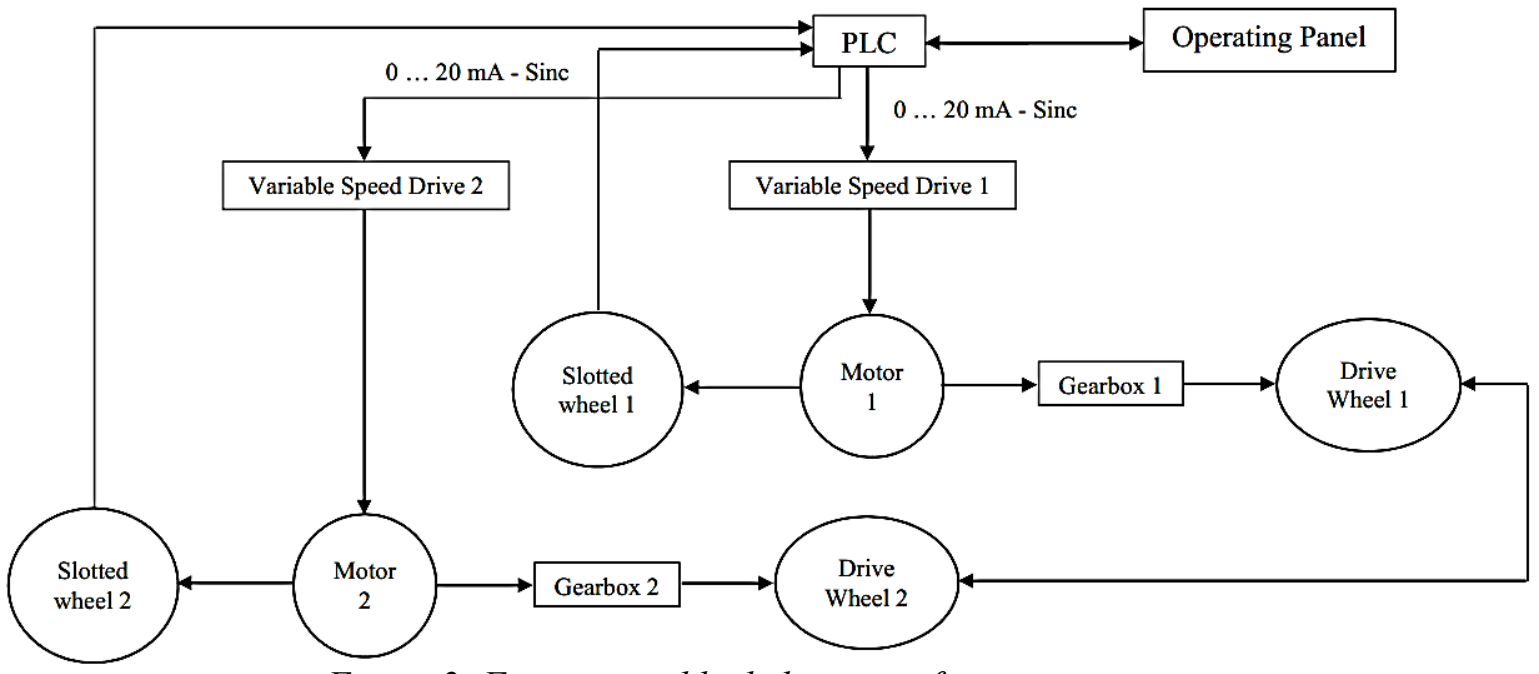

Figure 2: Functioning block diagram of automatic system

Using drive-end drum diameter value we determine with relations (1) and (2) maximum speed of first conveyor belt having value of $10.91 \mathrm{~m} / \mathrm{min}$.

$l=\pi \cdot D=3.14 \cdot 0.3 \mathrm{~m}=0.942 \mathrm{~m}$

$v_{1}=\frac{n_{2} \cdot l}{t}=10.91 \frac{\mathrm{m}}{\mathrm{min}}$

where, $1=$ unfolded diameter of drive-end drum, $\mathrm{n}_{2}=$ (maximum) speed of gearbox and $\mathrm{t}=$ time unit considered for conveyor belt movement.

In the same manner we determine maximum speed of second conveyor belt, which has the drive-end drum diameter of $0.16 \mathrm{~m}$ and it results $\mathrm{v}_{2 \max }=7.54 \mathrm{~m} / \mathrm{min}$.

For the synchronization we consider that speed of the two conveyers must have the same value and maximum functioning speed of the system mustn't exceed $v_{2 \max }$. Knowing the functioning speed of first conveyor we know the functioning speed of the second conveyor. With this value we determine variable speed drives frequency, using relation (2), (3) and (4).

$i=\frac{n_{\text {in }}}{n_{\text {out }}}$

$n_{\text {in }}=\frac{60 \cdot f}{p}$

where, $\mathrm{n}_{\text {in }}=$ input speed, motor speed for this application, $\mathrm{n}_{\text {out }}=$ the output speed, gearbox speed for this application, $f=$ the output frequency of the variable speed drive and $p=$ the number of pole pairs of the stator winding.

For this application, standard grid frequency is $50 \mathrm{~Hz}$ and, for this value, number of pole pairs of first conveyor is $p=4$ and number of pole pairs of second conveyor is $\mathrm{p}=2$.

Thus, we obtain a frequency of $9 \mathrm{~Hz}$ for variable speed drive of first conveyor and a frequency of $13.33 \mathrm{~Hz}$ for variable speed drive of second conveyor.

Using as input data the values of the previously calculated operating parameters we correlate these values with the operating range of the PLC, which is $0-20 \mathrm{~mA}$ and we obtain corresponding signal values used by PLC to control belt conveyer system functioning speed: $3.6 \mathrm{~mA}$ for first belt conveyor and $5.33 \mathrm{~mA}$ for second belt conveyor.

The operator can adjust the speeds of the belts movement from the operator panel (figure 2). The M221 Schneider Electric PLC, shown in Figure 3, processes the data in the reverse order of the previous calculations and transmits as a command to the variable speed drive that translates the data and transmits the signal to the motor. 


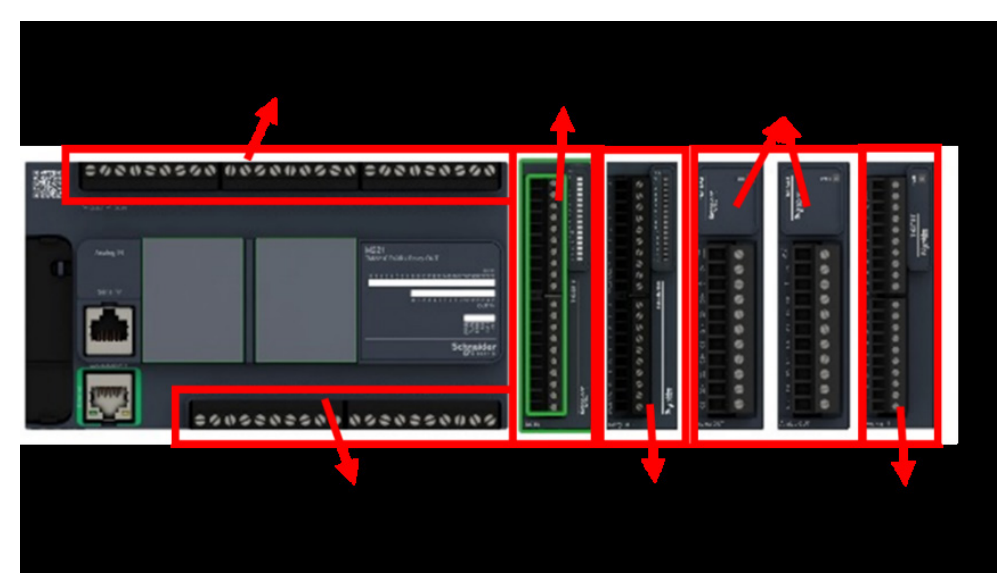

Figure 3: M221 Schneider Electric PLC

The Altivar ATV930 variable speed drive and the Altivar ATV312 variable speed drive, shown in Figure 4, receive the commands from the PCL on the analog inputs and processes it internally according to the parameters set at start-up (motor power, motor operating speed, starting ramp, stop ramp, grid frequency). The outputs of the variable speed drives result in a motor supply voltage with a frequency adapted to the input signal to determine the motor speed.

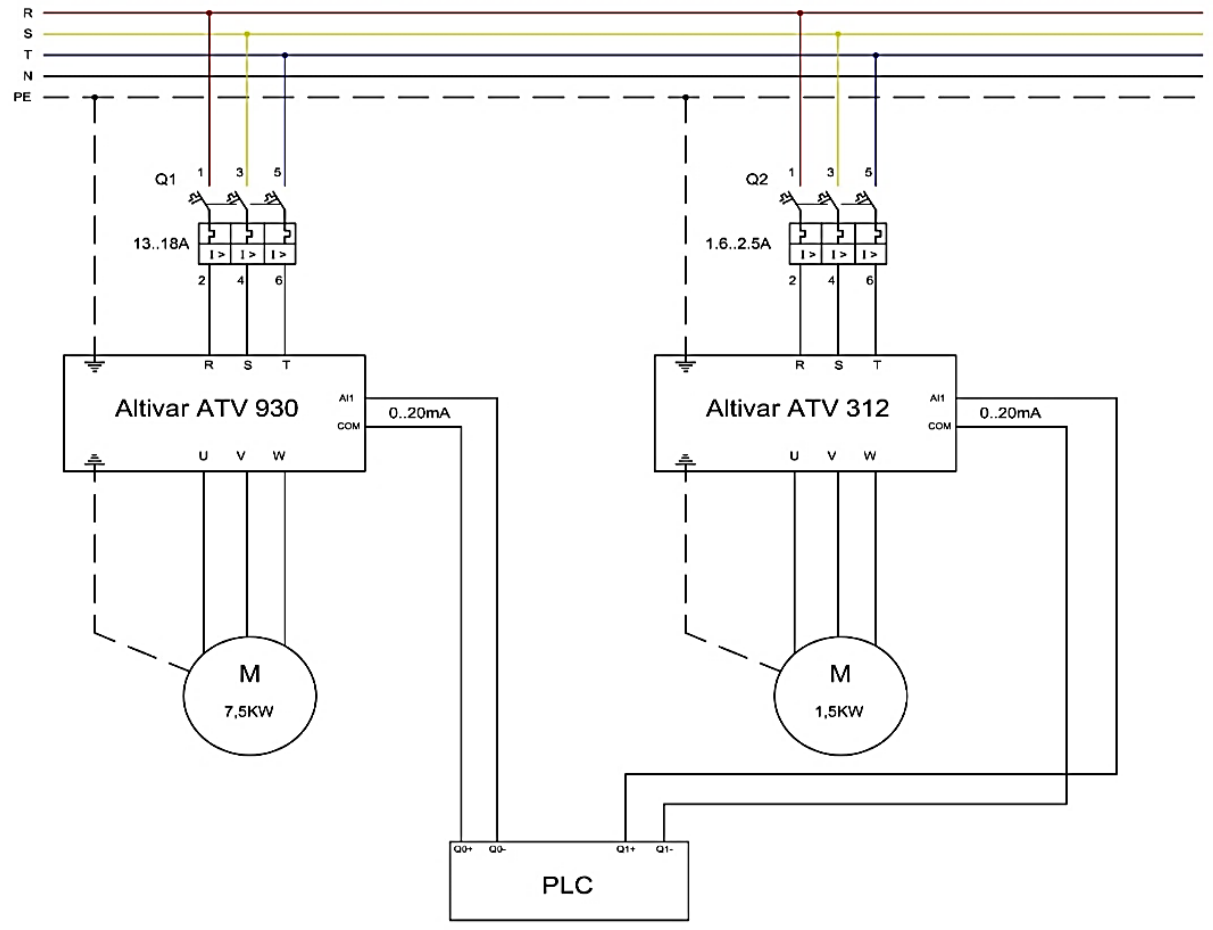

Figure 4: Electric scheme of variable speed drives connections

3. Implementing the solution for synchronized belt conveyers

Using the design earlier described the synchronized belt conveyer system was implemented as in pictures a) for first belt conveyor and $b$ ) for second belt conveyor, from Figure 5. Operating panel, which can be also seen in Figure 5. b), is set at the start of first belt conveyor. Here, the conveyor system operating parameters are set, as well as first belt conveyor speed is adjusted. 


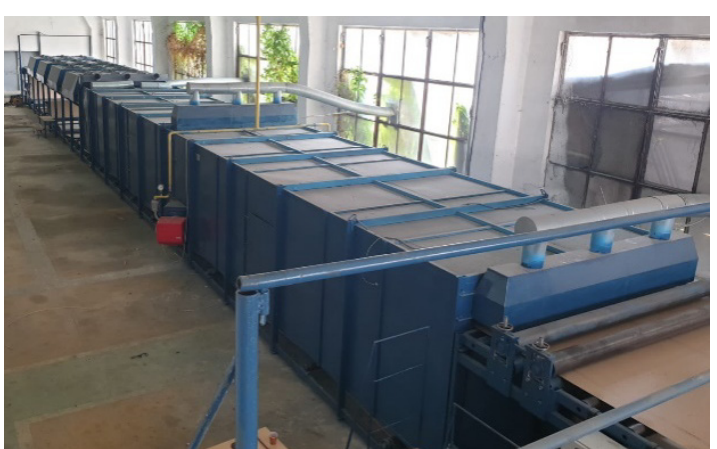

a) first belt conveyor

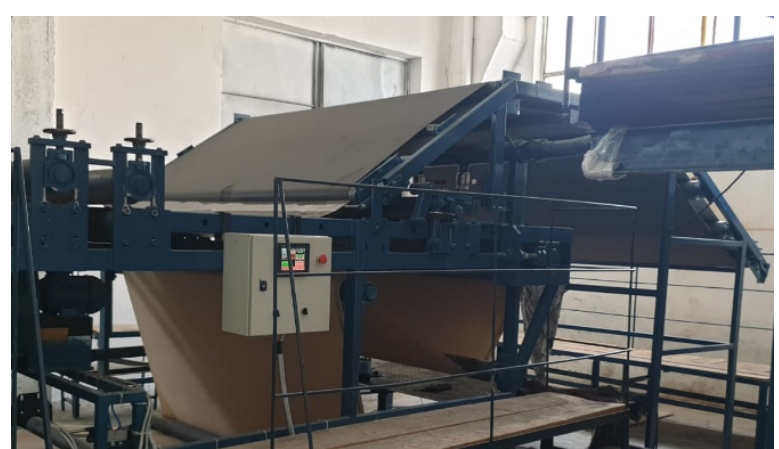

b) second belt conveyor and operating panel

Figure 5: Synchronized belt conveyor system

After the new speed value is given for first belt conveyor, it is transmitted as digital data to PLC (Figure 6. a) which processes received data, converts it into analog signal

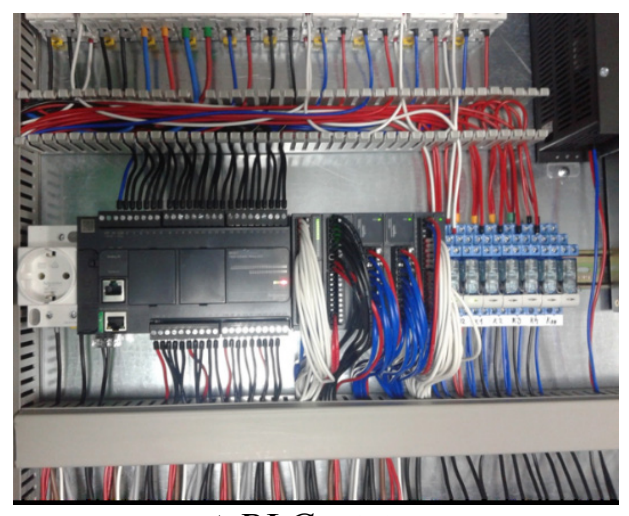

a) PLC wiring and sends the results as commands to variable speed drives of the two belt conveyers, shown in Figure 6. b.

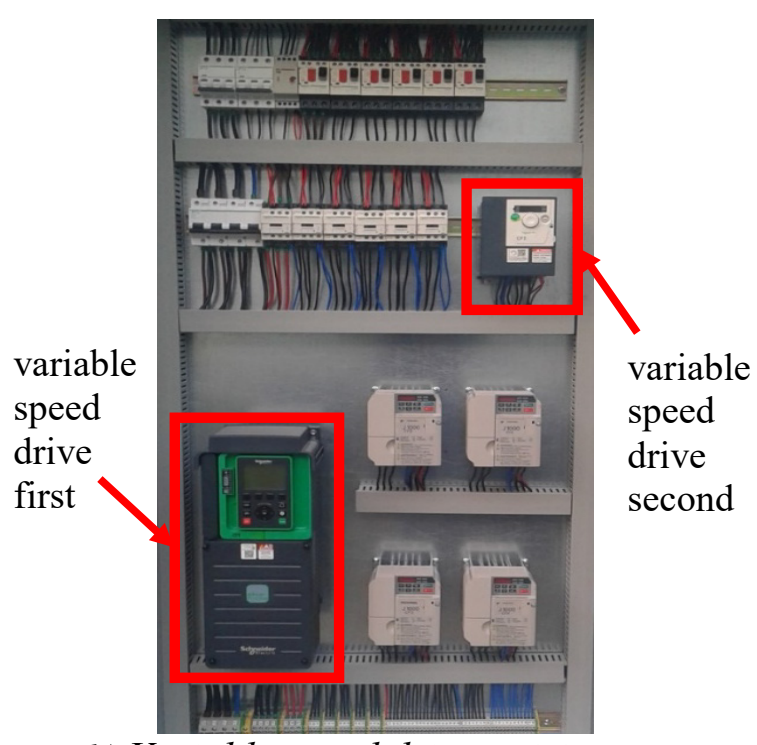

b) Variable speed drives wiring

Figure 6: Belt conveyor-automation part system

Each variable speed drive sends to corresponding motor drive a supply voltage with the frequency adjusted to input signal from the operating panel. The motor drive of first belt conveyor is mounted at the end of the cooling part and the motor drive of second belt conveyor is mounted at the beginning of the conveyor.

In order to have automatic control over speed adjustment precision, two slotted wheels were used. A 16-tooth slotted wheel was fixed on the motor shaft of the first belt conveyor with a wheel-mounted pulse transducer that transmits pulses to a digital input of the PLC encoder [4]. In the same manner, an 8-tooth slotted wheel was fixed on the motor shaft of the second belt conveyor with a wheel-mounted pulse transducer that transmits pulses to a digital input of the PLC encoder.

The range of the encoder is $0-200 \mathrm{~Hz}$, corresponding to the range of motors speed, $0-750 \mathrm{rpm}$ for the first motor and 0-1500 rpm for the second motor. Encoder's precision is of $1 \mathrm{~Hz}$ which corresponds to a $3.75 \mathrm{rpm}$ variation for the first motor and a $7 \mathrm{rpm}$ variation for the second motor.

Starting from relations (4) and (3) we can observe that the determined maximum deviation is $0.04 \mathrm{~m} / \mathrm{min}$ in belt conveyors synchronization. PLC is programmed to assure speed adjustment for the second belt 
conveyor in the range of $\pm 0.05 \mathrm{~m} / \mathrm{min}$. Thus, synchronization of the two belt conveyors is accomplished.

\section{Conclusions}

The belt conveyor system controlled by means of automation presented in this paper is designed for production of anti-slip door mats which are mainly used at inside door, decorative purpose, etc.

Conveyor design can be adjusted according to other production processes from a similar industry field.

Main advantage brought by the solution implemented for synchronizing conveyor system described in present paper is the high precision in speed adjustment assured by means of automation, mainly through the PLC and variable speed drives. The given solution is more suitable for belt conveyors which need motors with different speeds and gearboxes with different ratios.

\section{References List}

[1] Bebic M.Z., Ristic L.B., Speed controlled belt conveyors: Drives and mechanical considerations, Advances in electrical and computer engineering, Vol 18, No.1, 2018.

[2] Fabian Jordan, Schleuniger P., Detection and synchronisation of moving packaging units on a conveyor belt using a synchronised portal crane, International Conference on Industrial Process Control and Engineering Applications, Rome, Italy, January, 2021.

[3] Meshram P.A., Sahu A.R., Design, modelling and analisys of conveyor system used for transportation of cartons, International Journal of Research in Advent Technology, Vol 4, Nr 1, January 2016 Stroia M. D, Derbac D, Hatiegan C, Cîndea L, Thermostat Model With Arduino uno Board for Controlling a Cooling System, National Scientific

[4] Stroia Mihaela-Dorica, Hatiegan Cornel, Popescu Cristinel, Virtual Instrument Designed for Detecting Distortion Regime Caused by Frequency Variation, Analele Universităţii Constantin Brâncuşi din Târgu-Jiu - Seria Inginerie, Nr. 4, 2020.

[5] Stroia M.D, Hatiegan C., Popescu C., Virtual instrument designed for data acquisition, Studia Universitatis Babes-Bolyai Engineering, Vol. 65, Nr. 1, 2020

[6] Stroia M.D., Anghel D., Moșteanu D.E., Hațiegan C., Communication Interface Prototype Used for Data Transmission at Electric Systems, International Conference Knowledge-Based Organization, Vol. XXV, No 3, 2019.

[7] Vittorio Giovannetti et all, Conveyor belt clock synchronization, Quantum Physics, Rev. A 70, pp. 1-8, Cornell University, 26 May 2004.

[8] Ioan Pădureanu, Marcel Jurcu, Ladislau Augustinov, Cornel Haţiegan,Eugen Răduca, Laurenţiu Pădeanu, Optimisation of the Start-up and Operation Regimes of Cooling Water Pumps of a High-Power Hydro Generator, Analele Universităţii "Eftimie Murgu", Fascicula de Inginerie, Anul XXII, Nr. 1, 2015.

[9] Ioan Pădureanu, Marcel Jurcu, Ladislau Augustinov, Cornel Haţiegan, Eugen Răduca, Implementation of an Automatic System for the Monitoring of Start-up and Operating Regimes of the Cooling Water Installations of a Hydro Generator, Analele Universităţii "Eftimie Murgu", Fascicula de Inginerie, Anul XXII, Nr. 1, 2015.

[10] Eugen Raduca, Lucian Nistor, Cornel Hatiegan, Mihaela Raduca, Ioan Padureanu, Silviu Draghici, Web server for command, control and monitoring of industrial equipment, Advanced Topics in Electrical Engineering (ATEE), 2015 9th International Symposium on, 7-9 May Bucharest, 2015.

[11] M. Stroia, D. Moşteanu, I. Virca, E.Răduca, C. Popescu, C. Haţiegan, Case studies for automotive components using CAD and CAE techniques, International Conference on Applied Sciences ICAS 2019, May 9-11, Hunedoara, Romania, 2019. 